\section{Recent Developments in Radio Astronomy}

A recent issue of "Occasional Notes of the Royal Astronomical Society" $(3$, No. $16 ; 1954)$ is entirely devoted to the subject of radio astronomy and is made up of ten papers by Prof. A. C. B. Lovell and his colleagues at the Jodrell Bank Experimental Station of the University of Manchester. A short introduction by Prof. Lovell is followed by two chapters dealing with radio telescopes and techniques, copiously illustrated by plates and a number of diagrams. In these the main principles underlying the use of radio telescopes are explained, and the first chapter ends with a short account of two modern instruments: the large interferometer recently brought into use in Cambridge by M. Ryle; and the pencil-beam radio telescope under construction at Jodrell Bank, which, it is hoped, will be in use in 1955. After this, the remaining eight chapters deal with the application of radio astronomy and are arranged in order of distances from the earth as follows: meteors ; radio echoes from the aurora and the moon; radio waves from the sun; radio waves from the galaxy; the identification of the radio stars; the scintillation of the radio stars; radio waves from the interstellar hydrogen; radio waves of extragalactic origin. These provide adequate information for general readers interested in radio astronomy and are well illustrated (there are seven plates and twenty-seven diagrams altogether in the issue), and those who desire more extensive details will find in the bibliography a list of publications during the past eight years, several of which appeared in 1953 and 1954. Two points merit comment here. The first is that the origin of scintillations is not in the source itself but is due to varying atmospheric conditions; and, while these scintillations are very inconvenient to the radio astronomer, they provide a new technique to the geophysicist for investigating the complexities of the upper regions of the earth's atmosphere into which exploring rockets have not yet penetrated. The other is that among the normal nebulæ there may be distributed a class of nebulæ which are more powerful emitters than the normal spirals. It is difficult to say what peculiar property this class possesses, but there is support from different sources for the above suggestion, among which may be noticed the identification by Stanley and Slee of the intense sources in Virgo and Centaurus with the peculiar nebulæ NGC 4486 and NGC 5128, and the more recent identification of the intense source Cygnus 1 with two faint extra-galactic nebulæ in collision. Other lines of evidence also support the suggestion.

\section{Exchange of Students for Technical Experience}

THE remarkable increase in the number of technical students who obtain practical experience in other countries during their long vacations is shown in the seventh annual report of the International Association for the Exchange of Students for Technical Experience. During 1954 the number of effective exchanges made has been 4,267 students, showing a further increase of 484 over the 1953 total. In addition, 148 students were placed between Turkey and member countries of the Association. Portugal was admitted to the Association in January 1954, and India and Turkey have made application. for admission. Difficulties are being encountered in the United States in forming a central committee for the exchange of students, although many industries have signified their readiness to receive students, and the U.S. State Department has expressed willingness to facilitate the admission of students by the allocation of the necessary programme number to cover the issue of visas for visiting overseas students.

\section{University of Lonyon: Appointments}

THE following appointments in the University of London have been announced : Dr. A. W. Skempton, reader in soil mechanies at the Imperial College of Science and Technology, to the University chair of soil mechanics tenable at that College; Dr. D. G. Harvey to the University readership in chemical pathology tenable at the Royal Veterinary College; Prof. Norman Millott, professor of zoology in the University College of the West Indies, to the University chair of zoology tenable at Bedford College in succession to Prof. H. Munro Fox.

\section{Announcements}

The 1955 James Watt International Medal of the Institution of Mechanical Engineers has been awarded to Dr. Igor Ivan Sikorsky, in recognition of his life's. work in applying science to the progress of mechanical engineering through pioneering development of aircraft of various types-multi-engined, amphibians and particularly helicopters. The James Watt International Medal was founded to commemorate the bi-centenary of the birth of James Watt on January 19,1736 , and is the Institution's highest award.

ON the occasion of the Fourth World Petroleum Congress to be held in Rome during June 6-15, an International Oil Equipment Exhibition will be organized in Naples, in the premises of the Overseas Fair (Mostra d'Oltremare). This Exhibition will remain open during June 5-20.

Tere group of European molecular spectroscopists, which held moetings at Basel in 1951 and Paris in 1953, has arranged to hold another meeting in Oxford during July $7-11,1955$. The subjects discussed will cover a wide range of ultra-violet, infrared and Raman work. Further information may be obtained from Dr. H. W. Thompson, St. John's College, Oxford.

A CONFERENCE on "The Functions and Education of the Chemical Engineer in Europe", organized by the Institution of Chemical Engineers in co-operation with the Department of Scientific and Industrial Research for the European Productivity Agency of the Organization for European Economic Co-operation, will be held at Church House, Westminster, London, S.W.1, during March 21-23. Eleven Western European countries are expected to take part. The conference is open to official delegates and members of the Institution of Chemical Engineers. Further information can be obtained from the Institution, 56 Victoria Street, London, S.W.1.

THE third annual meeting of the editorial board of the Journal of Embryology and Experimental Morphology will be accompanied by a conference on embryology to be held in the Palais des Académies and the Faculté de Médecine in Brussels during April 4-7. Those wishing to attend are asked to inform Prof. A. M. Daleq, 97 rue aux Laines; Brussels, as soon as possible. (Those travelling from Britain should communicate instead with Dr. D. R. Newth, Department of Zoology, University College, London.) Requests for accommodation in Brussels must be made before February 1. 